\title{
VÍCTIMAS DE LA MODA \\ EN LA NARRATIVA DE EMILIA PARDO BAZÁN: \\ ROSA NEIRA Y PILAR GONZALVO
}

\author{
Blanca Paula Rodríguez Garabatos \\ Universidad de La Coruña
}

\section{RESUMEN}

El interés por la moda es utilizado por Emilia Pardo Bazán como un recurso narrativo para caracterizar la psicología de sus personajes femeninos, muchos de los cuales (Rosa Neira, Pilar Gonzalvo) no serían tan complejos ni interesantes si Pardo Bazán no nos hablase de sus vestidos o su obsesión por los trapos.

PAlabras ClaVe: narrativa, fashion victims, moda como recurso literario, psicología.

\author{
VICTIMS OF FASHION \\ IN THE NARRATIVE OF EMILIA PARDO BAZÁN: \\ ROSA NEIRA AND PILAR GONZALVO
}

\section{Abstract}

The interest in fashion is used by Emilia Pardo Bazán as a narrative resource to characterize the psychology of her female characters, many of whom (Rosa Neira, Pilar Gonzalvo) would not be so complex nor interesting if Pardo Bazán did not talk to us about her clothes or her obsession with rags.

KEYWORDS: narrative, fashion victims, fashion as a literary resource, psychology. 
El concepto de fashion victim designa a aquella persona que excede los límites comunes de vestir a la moda. Se trata de sujetos vulnerables al materialismo y a las modas pasajeras y que están demasiado pendientes de su consideración social, de su apariencia y de las últimas tendencias. Su afán por no perderse las novedades las impulsa a gastar compulsivamente y a cambiar constantemente de vestuario con tal de no perder su predicamento ni como adalides del lujo ni como iconos de estilo y belleza.

La condición de fashion victim está perfectamente descrita y caracterizada por Emilia Pardo Bazán a través de los numerosos personajes femeninos que pueblan su vastísima obra narrativa y sucumben a la pasión por los trapos. "Alma de las fiestas y tormento de las modistas» (1990, III: 361) es una perfecta definición de fashionista que dońa Emilia aplica en el relato El contador a su protagonista, Ángeles Luzán, y que podríamos hacer extensible a cualquier mujer que se divierte y disfruta con la moda (Huizinga 2005: 14). La moda permite ser uno mismo, celebrar la individualidad de manera mundana y, al mismo tiempo, mostrarse original ante los demás (Lipovetski 1990: 51, 52, 65). Esta finalidad es perfectamente compatible con otras legítimas aspiraciones.

Si tenemos en cuenta que la moda es, para sus adeptas, una idolatría escópica cuyo fin último es estimular los sentidos de quienes observan, su culto debe ser practicado en público. Por eso, el primer objetivo de toda devota fashion es lucirse ante los demás, destacar y distinguirse del resto. En Doña Milagros, el señor Neira reflexiona sobre el tema hablando de sus hijas:

Cuando el enjambre juvenil se echó a la calle a visitar iglesias, luciendo los trajes majos, de seda negra arrasada, profusamente adornados con cintas, y las mantillas sujetas con unos alfileres de piedras antiguas que habían pertenecido a mi Ilduara, produjo sensación (Pardo Bazán 1999a, III: 755).

En Una cristiana, Portal dice a Belén, amante oculta de un ricachón: «¿De qué te sirven los trajes majos ni los aretitos de piedras, si no puedes ir al Retiro a lucirlos?» (Pardo Bazán 1999c, III: 170), haciendo hincapié de nuevo en el hecho de que el lujo está hecho para ser disfrutado, pero sobre todo para ser exhibido (Veblen: 119-121).

La conquista del varón parece ser otra de las principales intenciones de las fashion victims (Flugel 1964: 38) ${ }^{2}$. El poder de seducción de la moda, que en sí misma es una "pasión infinitamente más violenta y terrible que la afición amorosa", se ve subrayado por Mauro Pareja en Memorias de un solterón cuando afirma rotun-

${ }^{1}$ Veblen atribuye al vestido una naturaleza espiritual que se rige por la ley del derroche ostentoso. Por un lado, la necesidad de comprar un vestido caro responde a la exigencia de acomodarse a un modelo social establecido. Por otro, esta costumbre responde a la idea de que lo barato es ridículo y privado de gusto.

${ }_{2}^{2}$ La moda satisface dos tendencias contradictorias, ocultar (ética) y exhibir (estética) el cuerpo. 
damente «que a no mediar el deseo de agradarnos a nosotros, no se compondría la mujer» (Pardo Bazán 1999b, III: 815).

No obstante, hay otros motivos por los que una mujer se arregla y compone que no tienen nada que ver con el deseo de seducir. Uno podría ser el arte por el arte, el mero placer de adornarse y otorgar valor a la propia apariencia (Deslandres 1987: 99): "Yo he llegado a creer - dice el Abad- que esta es una de las muchas infundadas fatuidades masculinas, y que la mujer no se compone por nosotros, sino más bien por el gusto de componerse y emperifollarse, por el arte puro» (Pardo Bazán 1999b, III: 815).

Otras veces, la fashionista desea generar envidia en quienes la contemplan y aspira a aparentar, brillar, competir y vencer (Squillace 1912: 18), tal y como señala, de nuevo, Mauro Pareja en Memorias de un solterón:

Y quizá, caso de impulsarla un móvil interesado, la impulse antes que el ansia de conquistarnos, el deseo de lucir, de brillar entre las amigas, de eclipsar a las otras mujeres y que estas rabien de envidia y de vanidad mortificada (1999b, III: 815).

La misma novela constata el deseo de toda mujer adicta a la moda de convertirse en «reina social» y centro de los ecos de sociedad de su entorno, aunque sea para que la critiquen por sus excesos:

Me consta (aquí bajaban la voz las noticieras) que compró en La Ciudad de Londres - ¿no sabe V.? ¿esa tienda que dicen que facilitó para ella los fondos Sobrado?unos encajes anchísimos, soberbios, para enaguas y peinadores. Nada, igual que una novia... ¡Cómo está el mundo, hija! Pasman las cosas que se ven... ¿ Y de dónde saldrán esas misas? Al padre parece que ya solo le falta por hipotecar las narices (1999b, III: 815, 816).

Finalmente, el afán por consumir ropa, el hambre insaciable de novedades (Berman 2001: 90) ${ }^{3}$, es otro leitmotiv que puede generar un enorme sufrimiento moral a la fashionista insatisfecha. El señor Neira da fe de este anhelo irrefrenable expresado por su hija Rosa en Doña Milagros: «Aquella tarde Rosa vino a decirme que estaba desnuda, que iba a aliviar el luto, y que ella y sus hermanas necesitaban ropa como el pan» (1999a, III: 740).

La sensatez no es uno de los adornos de la mujer en busca del éxtasis frívolo del yo (Lipovetsky 1990: 52). La moda impone sacrificios de muy diversa índole a sus seguidoras. Uno de ellos es la delgadez. En Por Francia y por Alemania menciona doña Emilia las penurias que padecen, en el balneario de aguas termales de Karsbald:

${ }^{3}$ El 'traje de moda' se caracteriza por los continuos cambios. Es este cambio el que produce una fractura en el carácter cíclico del tiempo que modifica la vigencia de la tradición. La repetición de una costumbre continua y constante se encuentra interrumpida por una nueva modalidad, totalmente contraria y opuesta a ella. 
Las señoras, atacadas de precoz obesidad, a quienes se les vuelve grasa todo cuanto comen y para quienes la operación de ceñir el corsé es un suplicio. Vienen a sufrir a trueque de adelgazar $2 \mathrm{~cm}$, de adquirir para el invierno una silueta hermosa y un volumen razonable, compatible con vestir a la moda (2004: 372).

La condesa, dueña de una oronda figura, bien debía de conocer estas frívolas torturas (Budiel 2019: 313)4. La obesidad es también un problema para Mercedes, protagonista de Allende la verdad, a quien la condesa describe como «mujer que tiene vida sentimental y es un poco jamona" y que, por ese motivo, cuida "prolijamente su tocado y su atavío» (Pardo Bazán 2002, VI: 306).

La ropa, aunque ayude a disimular los excesos de un cuerpo grueso, no obra milagros. La protagonista de Dulce Dueño, Lina Mascareñas, parece que no confía demasiado en que el vestido pueda disimular los estragos de la obesidad:

Mi figura es una de tantas como la moda actual, artísticamente pérfida y reveladora, troquela en sus moldes. Tiene trazos graciosos, [...] pero lo mismo les sucede a casi todas las que se visten de este modo, a menos que sean cincuentonas, o su estructura se base en el tocino o la cecina (Pardo Bazán 1989: 130).

La gordura no es glamourosa 5 . Incluso la santidad es esbelta. Santa Catalina de Antioquía es descrita en Dulce Dueño como una «figura dianesca, lanzal y erguida» (Pardo Bazán 1989: 79).

El relato La Sor insiste en la delgadez como sinónimo de virtud y belleza. Sor Marcela, la monja protagonista, es alabada como «una criatura delgada y menuda». Su hermana Clara, por contraste, es calificada como «una mujerona basta, ya algo ajamonada a los veintiséis, de protuberantes curvas y cutis encendido». La esbeltez de Marcela es un atributo más de su hermosura presidida por «un delicioso semblante infantil» (Magli 2013: 386 y Pardo Bazán 1990, III: 59). La gordura de Clara resalta su vulgaridad ante los ojos de Antonio, su recién estrenado esposo y pretendiente de Marcela tres años atrás.

El cuento La pasarela insiste en este debate acerca de «cuáles valen más, si las mujeres de libras o las menuditas y flacas» y señala que dicha cuestión es motivo de "constante disputa, y que entretenía muchas tardes y no pocas noches los ocios" masculinos. Los admiradores de la primera actriz de la compañía de teatro italoaustríaca protagonista del relato elogian su "pantalla espléndida, y su exuberancia de

${ }^{4}$ Pardo Bazán lamenta su gordura durante su romance con Galdós y le escribe en una de sus cartas: «iEste cuerpo del diablo! ¿Cómo haríamos para que yo me convirtiese en aérea sílfide que no dobla sus pies ni el cáliz de los lirios?» (Burdiel 2019: 313).

5 En La Physiologie, de Brillat Savarin publicada en 1826, se asocia por primera vez negativamente obesidad con estética y se señala que la gordura perjudica la belleza (Jáuregui Lobera 2006: 304). «La mujer moderna quiere estar delgada y no falta quien diga a su doctor: envenenadme, pero ¡hacedme adelgazar!» (De Burgos 2018: 70).

${ }^{6}$ Los estragos del paso del tiempo desfiguran el rostro y lo vuelven irreconocible para propios y extrańos. 
formas». Sus detractores la critican por «ajamonada» y prefieren a la actriz genérica, la Noquita, descrita como «especie de diablillo pequeño y vivaracho [...] con paso de sílfide, graciosa como un muchacho» (Pardo Bazán 1990, III: 188).

Silvio Lago, el árbitro de la elegancia de La Quimera, ratifica la beatitud de la delgadez y se muestra intransigente con las redondeces de la duquesa de Calatrava, "ex belleza del reinado de Alfonso XII», a la que califica de "fardo» y cuya gordura desdibuja su antigua belleza: «La obesidad, desbaratando las facciones finas, apenas permitía adivinar lo que pudo ser el antańo gracioso semblante». Además, Silvio también censura con dureza que la duquesa emplee su escote, única parte del cuerpo femenino en donde la abundancia de grasa es consentida y admirada, como reclamo seductor: "i $\mathrm{Y}$ el escote! Lo adivino. Veo asomar los encantos, como dos medias vejigas de grasa» (Fogg 2014: 177) ${ }^{7}$. En cambio, Lago se revela mucho más tolerante con los estragos de la vejez de otra de sus clientas porque se conserva delgada: «La Camargo, flaca, cobriza teñida, de tez estropeada por el artritismo, bien corsetada, silueta aún elegante y juvenil, indignó a Silvio un poco menos» (Pardo Bazán 1991: 226).

La vejez también es un problema para las fashionistas (Sánchez Palacios 2004:12) ${ }^{8}$. Cuando la protagonista de Dulce Dueño, Lina Mascareñas, describe a la duquesa de AmbasCastillas, hace hincapié en el esmero del arreglo de la aristócrata, quien

Se presenta, ágil y airosa y envelada la cara de tules (Magli 2013: 29-30) ${ }^{9}$, a fin de disimular y suavizar el estrago que los años han ejercido, impíos, en su belleza célebre. [...] en su maceramiento de sesentona, persiste una gracia arrogante que yo desearía imitar (1989: 226).

En el cuento John, el protagonista se queja de que su mayordomo inglés solo acepta entregar cartas amorosas a mujeres que sean "first class lady [...] y no permite un devaneo con una cursi, aun dentro de la buena sociedad, [...] no tolera sino a la media docena de señoras chic», a quienes el protagonista critica y rechaza porque están ajadas (Magli 2013: 40) ${ }^{10}$ : «Como sabes, jestán ya muy défraîchies!» (Pardo Bazán 1990, III: 15). También el relato Memento ridiculiza el arreglo excesivo e inapropiado de doña Aparición, una solterona ya mayor:

El peluquín de doña Aparición, con bucles y sortijillas de un rubio angelical, su calzado estrecho, sus guantes claros de ocho botones, sus trajes de seda a rayas

7 La duquesa de Calatrava todavía sigue en 1905 la moda de los escotes pronunciados y de hombros caídos que impuso en Europa Eugenia de Montijo.

${ }^{8}$ En la tradición grecorromana la vejez era considerada como una desgracia, ya que conllevaba el declive físico y las enfermedades asociadas a la edad avanzada.

${ }^{9}$ Incide en la fascinación que ejerce el rostro velado sobre quienes lo escudrińan.

10 «¿Qué mujer de cuarenta años no reconocerá en la toilette una profunda ciencia?» (Balzac 1974: 71). 
verde y rosa, sus abanicos de gasa azul y el grupo de flores artificiales que prendía graciosamente su mantilla, nos daban harto que reír (1990, I: 271).

En El cuarto no solo se censura la vulgaridad del arreglo de una misteriosa mujer que irrumpe en el palacio episcopal de Arcayla, también se cuestiona su edad aparente:

Para ojos inexpertos, ignorantes de ciertos artificios del tocador ${ }^{11}$, la dama... o lo que fuese, representaba cuarenta años a lo sumo, para los inteligentes, sabe Dios si podrán añadirse a la cuenta cuatro lustros bien corridos (1990, I: 388).

En Tío Terrones se insiste en lo incomprensible del glamour en la vejez. La joven Zoila, «que era todo lo aficionada a componerse y emperifollarse que permitía su humilde estado", sorprendida e intrigada por la procedencia de los lujos asiáticos de su tía Hilaria, pregunta a esta: «¿Y quién ha tenío la ocurrencia de regalarle esa preciosidá a una [...], a una persona mayor...?» (Pardo Bazán 1990, II: 410). La juventud como cualidad importante en una mujer hermosa también se subraya en Consejero, cuando don Diego Vélez de Guevara contempla a su hermana Beatriz, una monja ya anciana y "alegre, reidora», fashionista en su mocedad, y exclama: « $\mathrm{O}$ h juventudes, venenos vitales, hervores de la sangre, fermentos de la fantasía!» (Pardo Bazán 1990, III: 360).

El baile del Querubin anticipa «la comprobación de la vanidad universal» incluso en la niñez. Algunas de las chiquillas que acuden al baile que da título al relato se entretienen con juegos frívolos y «se dedican a hacerse visitas o a salir de paseo, desde la sala a la antesala, muy peripuestas, luciendo ricas mantillas de guiñapos y abanicándose con la pantalla o el soplador» (Pardo Bazán 1990, I: 226). Otra fashionista infantil es la moribunda protagonista de Más Allá, quien, «indiferente a la muerte como aniquilamiento del ser físico, no la aceptaba como abdicación de la gracia y la belleza». Por este motivo, se acicala incluso el día en que va a recibir la extremaunción: «Se lavó con esencias fragantes y jabones exquisitos, hizo peinar esmeradamente la negra mata de pelo, se puso traje de blanco gro, y con sonriente coquetería prendió en la mantilla sus agujas de turquesa» (Pardo Bazán 1990, I: 301). La niña protagonista de Los rizos, que prefiere la muerte antes que acudir a una colonia de verano en donde determinan cortarle el pelo para despiojarla, es otro ejemplo de vanidad precoz: «No me quitaréis mis rizos, no tal». Esta negativa a verse privada de las «finas ondas del soberbio pelo» hace que, finalmente, la niñita empeore: - ¡Está consumidita! [...] ¡Qué color tan malo!» (Pardo Bazán 1990, III: 95, 96) y muera.

Con este catálogo de fashionistas Pardo Bazán demuestra que todas las edades de la mujer desde la infancia hasta la senectud pasando por las glorias de la juven-

${ }^{11}$ Señala que el maquillaje es una manera «di sfuggire all'invechiamento... mettere reparo al lavoro inessorabile del tempo» (Magli 2013: 40). 
tud y los encantos de la madurez sucumben a los juegos de la apariencia y la seducción y a los caprichos y veleidades de la moda.

\section{FASHIONISTAS IRREDENTAS: ROSA NEIRA Y PILAR GONZALVO}

En el sistema de la moda advertimos el resultado de una lucha simbólica que se refiere a la contraposición entre los que ocupan una importante posición social y los que aspiran a ella. Bourdieu observaba que, mientras que las clases bajas se concentran en bienes de primera necesidad, la clase media ya no se mueve por la urgencia sino por la consolidación de comodidades como la vivienda o un vestido nuevo. Estos elementos representan la pretenciosidad de esta mesocracia que trata de crearse una nueva identidad que remarca las apariencias en detrimento de la realidad. Entre las manifestaciones corpóreas, el buen gusto es indicativo de la posición y, por ende, del grupo social de pertenencia. Las fashionistas irredentas de las novelas de doña Emilia aspiran, con sus delirios trapísticos, a ser reconocidas como pertenecientes a una categoría social superior (Bourdieu 1998: 182).

Rosa Neira, «bella, coqueta y despilfarradora» (Pardo Bazán 1999b, III: 819), es, en Doña Milagros, la personificación de la devoción por la moda: «Podría afirmarse de ella que ni existía ni respiraba sino para emperejilarse» (ibidem: 663) y, en Memorias de un solterón, se abunda en su psicología:

Era Rosa una de esas mujeres fatales y vitandas, de quienes se dijo con expresiva frase que son como el toro, que acuden más al trapo que al hombre. Solo al ver las locuras que los varones cometen por una hembra se comprenden las que son capaces de cometer las hembras por un pedazo de tela bonita: pasión infinitamente más violenta y terrible que la afición amorosa (1999b, III: 814).

Rosa padece "la enfermedad trapera», febril, devoradora e invasiva: "Altísima fiebre la abrasaba al ponerse en contacto con cintas y mońos. Su vida no tenía más clave ni más norma que el tocado y el vestido» (Pardo Bazán 1999b, III: 814, 815, 819).

En Rosa Neira, el amor por la ropa es una característica inherente a su naturaleza. Hay casi un enfoque rousseauniano (Flugel 1964: 19, 20, 72) ) $^{12}$ la descripción de su personalidad fashionista:

Si volviésemos al estado paradisíaco, a la cándida desnudez de la aurora del mundo, Rosa, con su blanca mano, ensartaría las primeras conchas para el primer collar bárbaro, o tejería la primer guirnalda de silvestres flores (1999b, III: 815).

12 La vestimenta sirve para cubrir el cuerpo y gratificar así el impulso de pudor. Pero al mismo tiempo puede realzar su belleza, y esta fue probablemente su función más primitiva. 
El pecado de Rosa Neira reside en que, al igual que Lina Moros en $L a$ Quimera, no necesita el adorno para destacar: «En Rosa concurría una circunstancia que hacía más visible y escandaloso lo que daban en llamar su lujo: y era su belleza misma, su belleza triunfadora y resplandeciente» (Pardo Bazán 1999b, III: 818). La moda es algo superfluo para las hermosas porque en ellas, como en Rosa:

El más insignificante trapito causaba alboroto porque se veía de cien leguas. Los colores en ella parecían más vivos, los adornos más caprichosos y ricos, las flores más lozanas [...] en Rosa las telitas peseteras y las puntillas de a real adquirían un aire de opulencia, majeza y frescura que les centuplicaban el mérito y el precio. Rosa ponía la moda en Marineda, y como a toda reina social, se la criticaba y se la imitaba a destajo (1999, III: 818).

Rosa es calificada de "viciosa» (Pardo Bazán 1999b, III: 873) porque en ella la obsesión por el arreglo es un defecto que en otras mujeres se disculpa y perdona porque lo necesitan para camuflar su fealdad (Baudelaire 1974. 115) ${ }^{13}$.

Rosa es una fashionista de provincias que pretende seguir la moda y también influir en sus potenciales seguidoras. Desde este punto de vista, Rosa Neira, aunque «hace lo que puede», es un fraude ya que:

Pobrecilla! Su mundo ideal no estaba a su alcance [...] la pobrecilla, después de tantos esfuerzos, de consagrar exclusivamente su vida y sus escasos recursos a deslumbrar a Marineda y atraerse las censuras de todas las personas sensatas... iba mal, rematadamente mal, para alguien entendido y exigente en achaques de gusto, tan mal, que era un dolor (199b, III: 817).

\section{En Memorias de un solterón se insiste en el fracaso de Rosa:}

Yo comprendía que el supuesto «lujo asiático», el «boato» de la chica de Neira, era en realidad penuria, y que con aquellos cuatro pinguitos, en Madrid, Rosa no pasaría de ser una de las bellas cursis en quienes nadie repara (1999b, III: 817).

No obstante, aunque no pueda gozar de la aprobación y admiración de los expertos en moda, Rosa sí puede engañar con sus trucos de ilusionista a las provincianas menos ilustradas que ella:

En Marineda se criticaba acerbamente el «lujo asiático» que había dado en gastar la hija de D. Benicio Neira. Las devotas amigas de saber vidas ajenas, como Zoe Martínez Orante y Regaladita Sanz, se hacían lenguas del derroche, boato y locuras de aquella muchacha. «Nunca lleva dos veces seguidas el mismo traje», suspiraban

${ }_{13}$ Baudelaire ataca la falsa concepción del siglo xviri sobre la inmoralidad del artificio como vehículo de construcción de la belleza femenina y señala: «El artista filósofo encontrará fácilmente la legitimación de todas las prácticas empleadas en todos los tiempos por las mujeres con el fin de consolidar y divinizar por así decirlo su frágil belleza». La actitud de Rosa, lejos de ser un vicio, sería la más natural y loable según esta opinión de Baudelaire. 
levantando los ojos al cielo. «Ahí está -añadían- Remedios Veniales, que ha tenido la curiosidad de contarle los trajes a Rosa Neira, y ¿cuántos dirá V. que resultan? Resultan quince, ¡quince! (1999b, III: 816).

En realidad, estamos ante una maestra en el arte del disfraz. En su "pequeño teatro de la moda» (Fogg 2014: 286) ${ }^{14}$, Rosa Neira enmascara con toda clase de artificios su ropa vieja y desfasada y crea una imitación burda pero convincente que se acerca mejor al ideal de lo fashion que, para ella y para sus vecinas, es inalcanzable (Veblen 1998: 119) ${ }^{15}$.

El (vestido) negro, de seda brochada, emulaba a Proteo, según las transformaciones que sufría, ya por medio de lazos amarillos, ya de plegados verdes, ya de encajes blancos, ya de flecos de azabache, el cuerpo unas veces lucía escote cuadrado, otras una pañoleta, cuándo unas hombreras anchas, cuándo unas mangas de color pegadas la víspera (1999b, III: 817).

Rosa es una maga, una ilusionista, Rosa, que «hacía prodigios» (Pardo Bazán 1999, III: 663), va persiguiendo la utopía de seguir la moda, para lo cual

aguza el ingenio para variar de adornos sin comprar ninguno nuevo, volvía al revés los trajes, les añadía perendengues, volantes aprovechados, la pasamanería que guarnecía la falda subía al cuerpo, y a la falda bajaba el fleco de las hombreras, repartido en golpes... Veía en un escaparate algo nuevo y caro, suspiraba, daba cien vueltas en redor del vidrio [...] y en casa, con vejeces, imitaba al punto la novedad. Siempre estaba refrescando sombreros, improvisando cinturones, forrando manguitos o planchando encajes (1999a, III: 663).

Memorias de un solterón insiste en las mañas de Rosa para rehacer vestidos y engañar a sus vecinas haciéndoles creer que tiene más trajes y galas de los que realmente puede permitirse ${ }^{16}$ :

Los quince vestidos contados por Remedios Veniales en realidad no pasaban de seis, pero la maña de Rosa consistía precisamente en disfrazarlos con tal arte, que nadie pudiese decir al verlos: «Mascarita, te conozco». Aquellos pichoncitos caseros mudaban la pluma cada semana. [...] No le iban en zaga las metamorfosis del (vestido) blanco, con el cual logró Rosa chasquearme a mí, pues los visos y

${ }^{14}$ El Thèatre de la Mode fue una exposición itinerante de maniquíes de moda en miniatura de los mejores diseñadores de moda parisinos que se gestó ante la imposibilidad de realizar desfiles con trajes a tamaño real durante la II Guerra Mundial.

${ }^{15}$ En las aspiraciones de Rosa subyace el deseo irrealizable de seguir la moda impuesta por las clases pudientes. Veblen considera la moda como una forma distintiva que sitúa al hombre en una posición de la escala social puesto que la necesidad de ostentar supera las preocupaciones de cubrir el cuerpo.

${ }^{16}$ Rosa Neira hace buena la afirmación de Balzac: «Toda moda que tiene por objeto una mentira es esencialmente pasajera o de mal gusto» (Balzac 1974: 75). 
cubiertas que recibía el traje lo hacían parecer enteramente distinto, inédito. ¡Qué diré de cierta casaquita de veludillo azul, ora guarnecida con densa piel, a la usanza rusa, ora velada por vaporosas gasas que remedaban nubes sobre un celaje puro! (1999b, III: 817).

En cualquier caso, toda imitación no deja de ser un lastimoso artificio fallido. De Rosa Neira dice compasivamente el solterón:

Yo sabía perfectamente que tan laboriosas combinaciones harían sonreír de lástima a una verdadera lionne, de las que encargan sus trajes por cajas y docenas, y desdeńan la ciencia humilde y práctica de aprovechar las sobras [...]. Aparte de que Rosa, en realidad, gastaba demasiado - pues esas vueltas y revueltas a un pingo, que al fin pingo se queda- [...] aquellas pobreterías - no me cabía duda- desequilibraban el presupuesto como lo podrían desequilibrar, si fuese mayor, los cajones llegados de París y las facturas del joyero y del peluquero de fama (1999b, III: 817).

No obstante su pobreza, toda fashionista que se precie antepone el gasto en vestir a cualquier otra necesidad personal o familiar. Las hijas de Neira son un ejemplo claro. Feíta Neira, en Doña Milagros, censura a sus hermanas en una conversación con su padre por este motivo:

Tula, que no tiene bonito sino el pie, ha derrochado un dineral en calzado y medias [...] Rosa, se pierde la cuenta de lo que se le va en perfumería, en guantes, en alfileres de azabache en macacadas por el estilo (1999a, III: 719).

No solo es importante la cantidad de ropa que luzca, sino también la calidad de la misma. Una víctima de la moda únicamente viste los tejidos más nobles y a ellos suma los complementos más exquisitos. Rosa Neira, amén de los quince trajes de los que presume, "iquince!, todos de seda o de raso, luce, a proporción los abrigos, los gorros (aún hay en Marineda quien llama así a los sombreros), los guantes, los abanicos, el calzado y todo lo demás» (Pardo Bazán 1999b, III: 816).

Concretamente, los excesos de Rosa Neira son también tema de reproche en Memorias de un solterón, en donde el sacrificio financiero del padre se pone, de nuevo, de relieve:

¿Cómo hablarle de la derrochadora Rosa, que en trapos y moños se gastaba lo que no tenía ni había de tener nunca, mientras su padre iba hipotecando la mitad de sus rentas al implacable Baltasar Sobrado, que le prestaba primero sobre los lugares de Cardobre, y después sobre otros no menos saneados y productivos? (1999b, III: 811).

Más adelante, en otro lugar de la misma obra se dice: «Para Marineda, y sobre todo para la menguada renta de D. Benicio, el teje maneje de trapeteo en que andaba Rosa era excesivo y alarmante» (Pardo Bazán 1999b, III: 817). Rosa, añade su hermana Feíta abundando en el tema, "estaba predestinada a este desenlace, si no encontraba inmediatamente un marido muy rico. Y si encontraba ese marido, estaba predestinada a arruinarle y a cubrirle de vergüenza» (Pardo Bazán 1999b, III: 913). 
Rosa será víctima de su vanidad. Sus aspiraciones de reina social no solo arruinan y desangran a su familia (Balzac 1974:75) ${ }^{17}$, sino que la conducen a la deshonra.

¿Qué te importa darnos la muerte y sepultarnos en basura? Como tengas tus trapos [...] jtrapos malditos, cochinos trapos, que ponen a un hombre de bien en el caso en que yo me encuentro! Se pagará la cuenta, aunque fuese con gotas de mi sangre [...] No permitiré yo que crean que si la hija es una pindonga, el padre es un tramposo (1999b, III: 947).

Feíta, su hermana, no deja lugar a dudas sobre la bochornosa situación:

Se ha vendido, bueno: pero como es tan necia, como su pobre cabeza está tan vacía, ni venderse supo, y lo que hizo fue ponerse la argolla de esclava, y a mi padre también. D. Baltasar Sobrado, es, como V. no ignora, una hormiguita. Tiene a papá sujeto con préstamos que le va facilitando. Puede, cuando le plazca, dejarnos en la miseria. Pues bien, Rosa, en vez de tratar - ya que iba al negocio- de conseguir la libertad de papá, de conservarle el pan de la vejez [...] ¿cómo dirá V. que cedió a las pretensiones de ese coscón vicioso? ¡Conviniendo Sobrado en que la garantizaría en las tiendas, sobre todo en la Ciudad de Londres, de donde la envían lo que pide sin presentar la factura! (1999b, III: 913).

Paradójicamente, el tormento de la fashionista deshonrada es la imposibilidad de exhibirse. Rosa Neira no podrá salir a la calle porque sería señalada por todos. Cuando, por fin, ha conseguido llamar la atención por su entrega a la moda, la sociedad la repudia por las vergonzosas artimañas que ha empleado: «Rosa no podía pagar, Rosa no se atrevía a salir a la calle, Rosa no tenía el recurso de acudir a Sobrado, ausente, marido ya de otra [...] -El primer momento fue de espanto tan grande, que Neira enmudeció» (Pardo Bazán 1999b, III: 945). Rosa expiará su culpa en casa y en bata «andaba por la casa despeinada y con una bata de zaraza de a real, indicio segurísimo en ella del dolor más verdadero» (Pardo Bazán 1999b, III: 961).

Con Rosa va a ser castigada también la vanidad de su padre. Rosa es una mujer objeto, ha sido el vehículo de lucimiento del señor Neira, siempre orgulloso de la belleza y del arreglo de la hija (Flugel 1964. 94) ${ }^{18}$ : «QQuién me diría -añadió el infeliz con súbita reacción de ternura- que habías de ser tú, Rosa, mi Rosiña [...] mi vanidad [...] la que ibas a darme el tósigo!» (Pardo Bazán 1999b, III: 947). Porque como dice a Feíta el solterón que da título a la novela: «El placer que nos causa o enchufado».

17 «Para ser elegante es necesario ganar una cuaterna, ser millonario, príncipe, sinecurista

${ }^{18}$ Flügel advierte que, desde principios del siglo xviII, el hombre comienza a preferir una estética más austera mientras que la mujer no se vio afectada por esta decisión masculina. En efecto, la mujer no solo no renunció a sus galas, sino que a través de estas se mostraba embajadora de los nuevos valores del hombre y por consiguiente de su proyección social. Tal es el caso de Rosa, vista como vehículo de exhibición de la posición social de su padre. 
ver a la mujer prendida con esmero y gusto, es lícito y hasta puro y noble» (Pardo Bazán 1999b, III: 873).

Pilar Gonzalvo, amiga de la protagonista de Un viaje de novios, es otro ejemplo de fashion victim llevado al extremo. Pilar, enferma de anemia, olvida su sufrimiento físico entreteniéndose con la moda:

Hambrienta como toda persona débil, como todo organismo pobre, de excitaciones, novedades y acontecimientos, divirtiole en extremo la relación nueva de Lucía, y las raras peripecias de su viaje, y el registro de sus galas de novia, que visitó sin perdonar una, examinando los encajes de cada chambra, los volantes de cada traje, las iniciales de cada pañuelo (2003: 162).

La Gonzalvo, a pesar de sus limitaciones físicas y sociales, presume de ser una experta conocedora y difusora de la moda: "La simplicidad franca de la leonesa (Lucía) le brindaba campo virgen e inculto donde plantar todas las flores exóticas de la moda, todas las plantas ponzoñosas de la maledicencia elegante» (Pardo Bazán 2003: 162).

Pilar es una aspirante a influencer pero nunca consigue la admiración que pretende: sufre «el paroxismo de un deseo no saciado, las ansias de la vanidad mal satisfecha» (Pardo Bazán 2003: 163). Pese a sus denodados esfuerzos, destacar es para ella una misión difícil porque no la acompañan ni la belleza ni la salud:

La primavera se había presentado para ella bajo malísimos auspicios, los conciertos de Cuaresma y los últimos bailes de Pascua, de los cuales no quiso perder uno, le costaron palpitaciones todas las noches, cansancio inexplicable en las piernas, perversiones extrańas del apetito: derivaba la anemia hacia la neurosis (2003: 164).

Pero la enfermedad no es un obstáculo para exhibirse cada vez que hay oportunidad. La Gonzalvo incluso se aprovecha de sus dolencias para conseguir acudir a los escenarios en donde se luce la moda: «Hacia el estío, se resolvió a quejarse, pensando acertadamente que la enfermedad era pretexto oportuno para un veraneo conforme a los cánones del buen tono» (Pardo Bazán 2003: 164). Gracias a estas oportunas quejas Pilar consigue veranear en la playa del Sardinero ${ }^{19}$.

Su afán por ejercer de socialité y estar presente en todos los saraos la lleva a extremos de sufrimiento físico, humillantes e incluso ridículos:

Pilar masticaba, a hurtadillas, raspaduras del pedestal de las estatuitas de barro que adornaban sus rinconeras y tocador. Sentía dolores intolerables en el epigastrio, pero por no romper el hilo de sus fiestas, calló como una muerta (2003: 164). 1986: 23).

19 Recordemos que el ideal de mujer romántica es el de una joven débil y enfermiza (Dijkstra 
Está claro que este personaje es la encarnación del proverbio «para lucir, hay que sufrir» hasta el extremo (Albar 2004: 154) ${ }^{20}$. Pero el sufrimiento de esta muchacha no radica solo en su malestar físico, sino también en un sufrimiento psicológico derivado del deterioro de su apariencia:

Lo que más la asustó fue ver que se le caía el pelo a madejas. Al peinarse, se enfurecía, y llamaba a gritos a Perico, pidiéndole un remedio para no quedarse calva. Un día el médico que la visitaba llamó aparte a su hermano, y le dijo: -Es preciso que tenga usted tino con su hermanita. Que no tome más bańos (2003: 164 $)^{21}$.

Aunque las tendencias de la época sean insanas y antigiénicas: «La civilización hace artificioso todo: si quiere sanar, que no trasnoche, que no ande en funciones [...] el corsé flojo, los tacones anchos» (Pardo Bazán 2003: 165). La enferma insiste en ir a la moda: «-Sí, sí, pide peras al olmo, al olmo -ceceaba Perico por lo bajo-. Cualquier día se pone mi señora hermana un alfiler menos, un alfiler menos, aunque se la lleve pateta». Pilar no se rinde a la enfermedad, solo claudica ante lo fashion: «Voy a hacerme un traje de tela cruda, que hasta allí... Bueno, bueno, hombre, no te pongas hecho una sierpe [...] Si ya sé que tengo que guardar método, y acostarme temprano [...] a las ocho con las gallinitas: ¿qué más pides?» (ibidem: 165, 166).

La hermana de Perico también es una víctima de la moda en el terreno económico y no duda en sangrar a "Gonzalvo padre, que amén de la jubilación no carecía de bienes, aflojó los cordones de la bolsa, no sin recomendar la parsimonia y economía a su hija». Pilar solo piensa en sus galas y en Vichy, su nuevo destino de exhibición personal: «El elegante viaje que con tanto lucimiento coronaba sus expediciones veraniegas» (2003: 166). Vichy es la perdición de Pilar. En este balneario sus desvaríos fashionistas llegan al paroxismo:

Estableciose desde entonces una lucha perenne entre Pilar y los que la acompañaban. Eran necesarios esfuerzos heroicos para contenerla e impedir que hiciese la vida de las bañistas del gran tono, que ocupaban el día entero en lucir trajes y divertirse (2003: 175).

En Vichy, las fashion victims se identifican entre ellas, se critican y rivalizan entre sí. Pilar distingue a las cubanas Amézaga «de cien leguas, por sus famosos sombreros, imposibles de confundir con otro tocado alguno" y con indisimulada envidia las critica después de cada encuentro:

${ }^{20}$ Una de las modas más inquietantes que se impusieron entre las cortesanas del siglo XVII fue la de masticar barro para mantener el rostro con una palidez mortuoria. Este parece ser el origen de los males de Pilar en Un viaje de novios.

${ }^{21}$ Patrizia Magli subraya la importancia del cabello para la belleza femenina, ya que es «la cornice del viso, la gloriosa corona che lo inghirlanda» (Magli 2013: 50 y 51). Carmen de Burgos señala que la calvicie es intolerable en la mujer (De Burgos Seguí 2018: 170). 
Un cuarto de hora lo menos quedaba Pilar murmurando de las petimetras y de alguien más también. [...] -iVamos, ¿te gusta a ti ese traje tan raro, con una cabeza de pájaro igual a la del sombrero, en el remate de cada frunce? Parecen un escaparate del Museo de Historia Natural (2003: 184, 185)22.

Exhibirse ante otras mujeres y provocar su admiración (Squillace 1912: 18) es el objetivo principal de la toilette de la Gonzalvo:

La presencia de las Amézagas, como les llamaba Perico, determinaba siempre en Pilar una especie de fiebrecilla que la dejaba postrada después para dos horas. Al divisarlas a lo lejos, se componía instintivamente el pelo, sacaba el pie calzado con zapatito Luis XV de tafilete, y paseaba su mano nerviosa por los morenos encajes de su pañoleta, haciendo destacar la flechilla de turquesas que la prendía (2003: 184).

La pobre enferma hace lo imposible por destacar entre la docena de «compatriotas de distinción que revoloteaban en el efímero torbellino de los placeres termales» (Pardo Bazán 2003: 175). No obstante sus esfuerzos, Pilar no triunfa en su aspiración y su hermano le reprocha: "Al fin nunca vas sino hecha una cursi, una cursi» (2003: 166). Quizás por esto, porque es consciente de su fracaso, Pilar prefiere la compañía de Lucía, «menos entendida en elegancias y modas» (2003: 174), porque es una amiga fiel, libre de vanidad, que la apoya en sus opiniones y críticas a las Amézagas y que no pretende eclipsarla en el terreno fashion. Por ejemplo, en el siguiente diálogo entre ambas, a propósito de un extravagante y carísimo abrigo que Pilar deseaba comprarse, Lucía acata con docilidad la autoridad de su amiga en temas de moda:

- Por eso hizo bien Perico en no comprarte aquel abrigo bordado de cuentas de colores que se te antojó. Era muy llamativo.

—No hay nada de eso [...] era distinguidísimo [...] ¿qué entiendes tú de esas cosas?

-Yo, nada -respondía Lucía risueña- (2003: 185).

Todas las mujeres fashionistas se desairan recíprocamente. Las cubanas Amézagas, en sus conversaciones con Pilar:

Hablaban como con pereza y desdén, mirando al cielo o a los transeúntes, e hiriendo la arena con el cuento de las sombrillas. Respuestas cortas e indolentes «hija, qué quieres», y «estuvo magnífico», "gente, como nunca», "pues ya se ve que estaba la sueca», "raso crema y granadina heliotropo combinados», "como siempre, dedicadísimo a ella», "sí, sí, calor», "vaya, me alegro que lo pases bien, hija», contestaban a las afanosas preguntas de Pilar. Luego se alejaban las cubanas, con carcajadillas discretas, con medias palabras, taconeando firme y moviendo un ruge-ruge de telas frescas y de ropa fina (2003: 184, 185).

22 Estas modas de sombreros gigantescos adornados con pájaros disecados fueron muy cuestionadas en la época en que se escribe la novela (Fukai et al., 2006: 300 y 301). 
La propia señorita Gonzalvo, al escuchar los elogios de Lucía sobre la blancura y hermosura de una clienta sueca de los baños, comenta: «-No te fíes de blancuras [...]. Habiendo en el mundo toalla de Venus y blanco de Paros» (2003: 195). La rivalidad entre mujeres es incluso internacionalizada en el salón de mujeres del balneario, en donde «el grupo de españolas, capitaneado por Lola Amézaga, que era muy resuelta, tenía cierta independencia e intimidad, bien distinta de la reserva secatona de las inglesas: y aún entre ambos bandos se advertía disimulada hostilidad y recíproco desdén» (2003: 197).

La enemiga de todas, imbatible en cuanto a estilo y belleza y odiada por sus alardes de independencia y por su desprecio a las convenciones sociales ${ }^{23}$, es la citada sueca:

Una mujer alta y gallarda [...], acrecentaba su clásica beldad el negro traje de tafetán, muy ceńido y golpeado de azabache, sobre su frente de diosa, el sombrero de tul con espigas de oro, parecía mitológica diadema, era su andar noble y soberano, y sin cuidarse de saludar a nadie, se fue hacia el piano, vacante a la sazón, y sentándose, comenzó a interpretar magistralmente unas mazurcas de Chopín (2003: 200).

Con ella se comparan todas, hasta la propia Lucía, la protagonista de la novela, mujer en absoluto vanidosa, quien bromea al respecto: «-No quiero eclipsar a la sueca» (2003: 194). A la beldad sueca quieren imitar y parecerse todas las bañistas de Vichy: ${ }_{-}$El traje de la sueca sí que sería bonito... crema y heliotropo! ¡me gusta la combinación!» (2003: 185), dice Pilar; «anímese usted, y yo la traeré un ramo de camelias como el que tenía anoche la sueca» (2003: 194), le dice Perico Gonzalvo a Lucía; «-Otro igual tenía ayer la sueca [...] Llevaba todo el juego: pendientes, collar de bolas de amatista y el agujón. Reguapísima que estaba la mujer con eso y el traje heliotropo", dice Lucía a propósito de un clavo de oro, "con cabeza de amatista, constelada de diamantes chiquititos» (2003: 198), que se quita del mońo para enseñarlo en una reunión de damas.

La sueca es el icono fashion de esta novela. Todas la idolatran, aunque la critiquen:

¡Parece la princesa Micomicona! -dijo Lola Amézaga, que aquella mañana no se había pasado menos de dos horas al espejo, ensayando el regio modo de andar de la sueca. - iQué empaque! -observó Luisa Natal-. No, buena moza, ya lo es. ¡Cuidado con el talle! ¡Y qué manos! ¿ No se las habéis reparado?. -Yo la miro poco -contestó Pilar-. No le doy ese plato de gusto. Solo adopta esos ademanes teatrales para llamar la atención! (2003: 202).

${ }^{23}$ La sueca encaja con el prototipo de mujer errante o rebelde que puede encontrarse en Londres o París. «Una mujer galante que se aplica y pone todo su genio así como toda su alma en su toilette» (Baudelaire 1974: 119). 
Y la sueca es la perdición de Pilar Gonzalvo. Por querer competir con ella luciendo en el baile del Casino un espejo portátil de «oro cincelado, joya caprichosa y novísima, que se colgaba de la cintura» (2003: 208), enferma y muere. Los preparativos para acudir a la fiesta son «un acceso de fiebre registrando su guardarropa»:

Durante la velada, Pilar llevaba un traje que hasta entonces no había usado por ligero y veraniego en demasía, una túnica de gasa blanca sembrada de claveles de todos colores, pendía de su cintura el espejillo, en sus orejas brillaban los solitarios, y detrás del rodete, con española gracia, ostentaba un haz de claveles. Así compuesta y encendida de calentura y vanidoso placer, parecía hasta hermosa, a despecho de sus pecas y de la pobreza de sus tejidos devastados por la anemia. Tuvo, pues, gran éxito en el Casino, puede decirse que compartió el cetro de la noche con la sueca. [...] uno de esos momentos únicos en la vida de una nińa vanidosa, en que el orgullo halagado origina tan dulces impresiones, que casi emula otros goces más íntimos y profundos, eternamente ignotos para semejantes criaturas. Las hermanas Amézagas contemplan y envidian su triunfo y se reconcomían mirando de reojo el espejillo, dije que solo brillaba sobre dos faldas: la de Pilar y la de la sueca (2003: 209).

Pero todo este esplendor aparente acaba trágicamente. La muerte de Pilar está anticipada por dońa Emilia Pardo Bazán en una escena en la que, de nuevo, el protagonista es el espejito:

Al vestirse, sus miembros no sostenían la ropa, que se escapaba del cuerpo como de un maniquí mal relleno. Ella misma se asustó, y en uno de los momentos lúcidos que suelen tener los atacados del terrible mal que ya la oprimía entre sus garras, pidió el espejillo famoso, y Lucía, por no contrariarla, se lo presentó de mala gana. Al fijar sus ojos en él, Pilar recordaba cómo se había visto la noche del baile, con sus claveles, su pelo artísticamente rizado, y la sonrisa de placer que le iluminaba el rostro. Fue tal el contraste entre lo pasado y lo presente, entre la cara de ocho días atrás y la de hoy, que Pilar, con rápido movimiento, arrojó al suelo el espejillo. Quebrose la clara luna, y las cinceladuras finísimas del marco se abollaron al golpe (2003: 213).

Rosa Neira y Pilar Gonzalvo ejemplifican el catálogo de necedades en las que incurren las mujeres que sucumben a la moda. Copiar desesperadamente figurines como hace Rosa, creer que se es elegante por incorporar todas las novedades, hacer de ciertos artículos una necesidad (el espejillo de Un viaje de novios) y jugar con la salud hasta extremos trágicos son algunas de las conductas desmesuradas y enloquecidas de estas mujeres sin tino ni acierto.

No pocas veces la moda es, según se desprende de los casos descritos por Pardo Bazán, algo más que un placer mundano. Es una religión demoníaca y una tiranía despótica que puede ser causa de la perdición de sus adoradoras y esclavas, sean estas santas o pecadoras, bellas o poco agraciadas, sanas o enfermas. En cualquier caso, la autora gallega también deja constancia de que la mentalidad decimonónica no perdonaba ni la exaltación de la belleza ni la declaración de independencia que muchas de las fashionistas retratadas por Pardo Bazán expresaron a través de su arreglo. 
Vanitas, vanitatum, omnia vanitas, dice el Eclesiastés. Si los placeres mundanos son inútiles ante la certeza de la muerte, la obra narrativa de la condesa de Pardo Bazán nos deja claro que la muerte de las ilusiones y esperanzas de las candidatas a reinas de la sociedad es, como certifican Rosa Neira y Pilar Gonzalvo, la única certeza posible.

Recibido: diciembre de 2019; aCePtado: junio de 2020 


\section{BIBLIOGRAFÍA}

Aibar, Óscar (2004): Los comedores de tiza, Madrid: Caballo de Troya.

Balzac, Honoré de (1974): Tratado de la vida elegante, Barcelona: Anagrama.

Baudelaire, Charles (1974): El pintor de la vida moderna, Barcelona, Anagrama.

Berman, Marshall (2001): Todo lo sólido se desvanece en el aire: la experiencia de la modernidad, Madrid: Siglo XXI.

Bourdieu, Pierre (1998): La distinción, criterio y bases sociales del buen gusto, Madrid: Taurus.

Burdiel, Isabel (2019): Emilia Pardo Bazán, Madrid: Taurus.

De Burgos Seguí, Carmen (2018): El arte de ser mujer, Pedro Gómez Carrizo editor, España: Biblok editores.

Deslandres, Yvonne (1987): El traje, imagen del hombre, Barcelona: Tusquets.

Dijstra, Bram (1986): Idols of Perversity: Fantasies of Feminine Evil in fin-de- siecle culture, Nueva York: Oxford University Press.

Fogg, Marnie (2014): Moda. Toda la historia, Barcelona: Blume.

Flugel, John Carl (1964): Psicología del vestido, Buenos Aires: Paidós.

Fukai, A., T. Suoh, M. Iwagami, R. Koga y R. NiI (2006): MODA: una historia desde el siglo XVIII al siglo XX. La colección del Instituto de la indumentaria de Kyoto, China: Taschen.

Huizinga, Johan (2005): Homo ludens: el juego y la cultura, Madrid: Fondo de Cultura Económica.

Jáuregui Lobera, Ignacio (2006): «Gordos, obesos y obsesos», Trastornos de la conducta alimentaria, n. ${ }^{\circ}$ 4: 295-320.

Lipovetsky, Gillles (1990): El imperio de lo efimero. La moda y su destino en las sociedades contemporáneas, Barcelona: Anagrama.

Magli, Patrizia (2013): Pitturare il volto. Il trucco, l'Arte, la Moda, Venecia: Marsilio editori.

Pardo BazÁn, Emilia (1990): Cuentos completos, tomos i, il y iII, edición de Juan Paredes Núnéz, Fundación Barrié de la Maza, La Coruña: Galicia editorial S.A., GAESA.

Pardo BazÁn, Emilia (1999a): Doña Milagros, Obras completas, tomo III, edición de González Herrán, Manuel y Villanueva, Darío, Madrid: Biblioteca Castro.

Pardo BazÁn, Emilia (1999b): Memorias de un solterón, Obras completas, tomo III, edición de González Herrán y Villanueva, Darío, Madrid: Biblioteca Castro.

Pardo BazÁn, Emilia (1999c): Una cristiana, Obras completas, tomo III, edición de González Herrán, Manuel y Villanueva, Darío, Madrid: Biblioteca Castro.

Pardo Bazán, Emilia (2002): Allende la verdad, Obras completas tomo vi, Novelas cortas, edición de González Herrán, Manuel y Villanueva, Darío, Madrid: Biblioteca Castro.

Pardo Bazán, Emilia (1991): La Quimera, edición de Marina Mayoral, Madrid: Cátedra, Letras hispánicas.

Pardo BazÁn, Emilia (1989): Dulce dueño, edición de Marina Mayoral, Madrid: Castalia, SA.

Pardo BazÁn, Emilia (2003): Un viaje de novios, edición de Marisa Sotelo Vázquez, Madrid: Alianza.

Pardo BazÁn, Emilia (2004): Viajes por Europa, Por Francia y por Alemania, Madrid: Bercimuel.

Pérez Galdós, Benito (1996): La de Bringas, Madrid: Alianza. 
SÁnchez Palacios, Concepción (2004): Estereotipos negativos hacia la vejez y su relación con variables sociodemográficas, psicosociales y psicológicas. Tesis doctoral, Málaga: Universidad de Málaga.

SQuillace, Fausto (1912): La moda, Milán: Palerino Remo Saudi editore.

Veblen, Thorstein (1998): Teoría de la clase ociosa, Madrid: Hyspamérica. 
